\title{
Lymphoproliferative responses to HIV-I Gag p24 antigen and mitogens in HIV-I subtype CRFOI_AE infected Thai patients and HIV-I seronegative donors
}

Thippawan Chuenchitra*1, Suchitra Sukwit ${ }^{1}$, Pittapun Chaitaveep ${ }^{1}$, Mark S de Souza ${ }^{1,2}$, Silvia R Kim¹,3, Robert M Paris ${ }^{1,2}$ and Sorachai Nitayaphan ${ }^{1}$

Address: ${ }^{1}$ Armed Forces Research Institute of Medical Sciences, Bangkok, Thailand, ${ }^{2}$ US Military HIV Research Program, Rockville, USA and ${ }^{3}$ Hawaii AIDS Clinical Research Program, University of Hawaii, Honolulu, Hawaii

* Corresponding author

from 2006 International Meeting of The Institute of Human Virology Baltimore, USA. 17-2I November, 2006

Published: 21 December 2006

Retrovirology 2006, 3(SuppI I):PI3 doi:10.1 186/1742-4690-3-SI-PI3

(c) 2006 Chuenchitra et al; licensee BioMed Central Ltd.

\section{Background}

Lymphocyte proliferation assay has been the standard assay to assess CD4+ T cell function. To determine lymphoproliferative responses (LPR) to HIV-1 p24 and mitogens of PBMC from HIV-1 subtype CRF01_AE infected Thai patients compared with PBMC from HIV-1 seronegative donors.

\section{Methods}

Frozen PBMC from 8 HIV-1 infected Thai patients and 8 HIV-seronegative donors were tested and compared for LPR to multiple concentrations of HIV-1 p24 antigen, phytohemagglutinin (PHA), and pokeweed mitogen (PWM). HIV-1 infected patients were grouped by the presence of CD $4+$ counts $>350[$ mean $=483.5 \mathrm{cell} / \mathrm{mm} 3, \mathrm{n}=$ 2 (group A)] or CD4+ counts $<350$ [median $=75.5$ cells/ $\mathrm{mm} 3, \mathrm{n}=6$ (group B)]. A stimulation index $>5$ was considered a positive LPR.

\section{Results}

Both HIV-1 infected patients and HIV-seronegative donors Thai demonstrated positive LPR to PHA and PWM $(8 / 8,100 \%)$. LPR to HIV-1 p24 were seen only patients in group A $(100 \%, 2 / 2)$, not in group B $(0 \%, 0 / 6)$. This difference was significant (Chi-square test $=11.0, \mathrm{p}=$ 0.0357).

\section{Conclusion}

This result suggests that CD4+ T cells in HIV-1 subtype CRF01_AE infected Thai patients with CD4+ counts $>350$ cells/mm 3 have ability to proliferate in response to HIV-1 p24 and indicate they remained the good CD4+ T cell function. 